\title{
LA REPRESENTACIÓN ZOOLÓGICO-SIMBÓLICA DE LOS SEDICIOSOS Y AGITADORES EN LOS SYMBOLA ET EMBLEMATA DE JOAQUÍN CAMERARIO
}

\author{
BEATRIZ ANTÓN \\ Universidad de Valladolid*
}

\section{Resumen}

Este trabajo estudia por primera vez los tres emblemas que Joaquín Camerario compuso a partir de motivos zoológicos tan dispares como el camello (Cent. II, emb. 15), la anguila (Cent. IV, emb. 45) y la salamandra (Cent. IV, emb. 70), pero unidos por un significado simbólico común: la representación de los sediciosos y agitadores sociales. Para ello, además de ofrecer la traducción anotada de cada emblema y del comentario que lo acompaña, identifico sus fuentes clásicas y humanistas, entre estas últimas los autores que fueron sus modelos directos de inspiración: Paolo Giovio, Andrea Alciato y Denis Lebey. En suma, el mundo natural representado en estos emblemas por un cuadrúpedo, un pez y un anfibio es susceptible de una interpretación ética y política, si bien Camerario, como luterano confeso, aprovecha la ocasión para censurar a los teólogos polemistas (Cent. IV, emb. 70).

Palabras clave: Joaquín Camerario, sediciosos, agitadores, camello, anguila, salamandra.

\section{THE SYMBOLIC-ZOOLOGICAL REPRESENTATION OF THE REBELS AND SOCIAL AGITATORS IN THE SYMBOLA ET EMBLEMATA BY JOACHIM CAMERARIUS}

\section{Abstract}

This paper studies for the first time the three emblems that Joachim Camerarius designed based on zoological motifs as different as the camel (Cent. II, emb. 15), the eel

\footnotetext{
* Este artículo se inserta en el Proyecto de Investigación del Plan Nacional de I+D PGC2018-094604-B-C31 (MCIU/AEI/FEDER, UE). Las fuentes griegas se citan por el Liddell-Scott-Jones, A Greek-English Lexicon, y las latinas por el Thesaurus Linguae Latinae.
} 
(Cent. IV, emb. 45), and the salamander (Cent. IV, emb. 70). All the three are linked by a common symbolic meaning: they represent rebels and social agitators. I offer an annotated translation of each emblem and the accompanying commentary, and I also identify their classic and humanist sources. Among the latter I focus on the authors who were Camerarius' direct models of inspiration: Paolo Giovio, Andrea Alciato and Denis Lebey. In sum, the natural world represented in these emblems by a quadruped, a fish, and an amphibian is susceptible to an ethical and political interpretation, but since the author was openly a Lutheran, he also took the opportunity to censure polemical theologians (Cent. IV, emb. 70).

Keywords: Joachim Camerarius, rebels, social agitators, camel, eel, salamander.

\section{LOS SYMBOLA ET EMBLEMATA DE JOAQUÍN CAMERARIO O EL MUNDO NA- TURAL EN CLAVE SIMBÓLICA}

Los Symbola et Emblemata del médico Joaquín Camerario (Núremberg, 1534-1598), publicados en Núremberg en cuatro centurias (la última póstumamente) ${ }^{1}$, supusieron un verdadero hito en la literatura emblemática al expresar el mundo natural (botánica y zoología en su caso) en el lenguaje arcano de los símbolos, y se convirtieron en obra de referencia para multitud de intelectuales, incluidos los oradores, predicadores y autores de enciclopedias, misceláneas y libros de lugares comunes.

Camerario, hijo del famoso helenista homónimo, consagró la última década de su vida a componer estas reflexiones filológicas y éticas ( $p h i$ lologicas \& ethicas meditationes), como define sus emblemas en la «Epístola dedicatoria» de la Cent. I (pág. A3r) (Antón, 2012: 158); y lo hizo en su tiempo libre (tempora subseciua) o mientras se recuperaba de su mala salud ( ob infirmiorem valetudinem). La colección -agrega recurriendo al tópico de la falsa modestia- es resultado de su escaso talento (a meo exiguo ingenio) y de la compilación de escritos ajenos, principalmente de autores italianos (ex alijs ac imprimis Italicis scriptis) ${ }^{2}$. Esta alusión a

${ }^{1}$ Cent. I. ex re herbaria (Camerario, 1590 [1-V-1593]); Cent. II. ex animalibus quadrupedibus (Camerario, 1595); Cent. III. ex volatibus et insectis (Camerario, 1596 [1-II1597]); Cent. IV. ex aquatilibus et reptilibus (Camerario, 1604 [1-II-1605]). Hay edición facsimilar (Harms y Kuegen, 1986-1988).

${ }^{2}$ Camerario, que estudió medicina en Padua y se doctoró en Bolonia (1562), sin duda conocía bien la lengua italiana. 
obras ajenas me lleva a apuntar sus principales fuentes ${ }^{3}$, que suele pasar en silencio. Ocupa un lugar preeminente el naturalista Conrad Gesner (1516-1565), apodado el Plinius Helveticus, quien con la Historia animalium (Zúrich, 1551-1558, 4 vols.) no solo abrió «una ventana al mundo emblemático renacentista» (Ashworth, 1990: 305), sino también «plantó las semillas de la aproximación emblemática a la naturaleza», semillas que Camerario haría florecer pocas décadas después (Ashworth, 1996: 329). Entre los tratados botánicos y zoológicos que manejó estaban, entre otros, los de Ulisse Aldrovandi, Prospero Alpino, Pierre Belon, Guillaume Rondelet, Ipolitto Salviani y Pietro Andrea Mattioli. La literatura simbólica está representada sobre todo por Andrea Alciato, Pierio Valeriano, Achille Bocchi, Claude Paradin, Paolo Giovio, Luca Contile, Girolamo Ruscelli, Camillo Camilli y Battista Pittoni.

Cada libro, o centuria, muestra una estructura simétrica: el emblema triplex (inscriptio, pictura, subscriptio) ocupa una página (la recta) y la otra se reserva para la explanatio en prosa. Precisamente, para Camerario esta explanación es el repositorio de información, suya o ajena, imprescindible para la inteligencia del emblema. Así lo corrobora el specimen manuscrito de la colección, de 1587 (Stadtbibliothek Mainz, Ms II, 366), titulado Symbola et Emblemata tam moralia quam sacra (Harms y Hess, 2009). Lo componen 200 emblemas que siguen un orden diferente al de la edición impresa, aunque en ambos casos es muy similar la estructura de cada emblema, que abarca dos páginas: una con el título, la pictura y el número del emblema (sin epigrama o subscriptio); y la otra con un texto en prosa, que el autor concibe no como un mero comentario adicional, sino como la verdadera subscriptio del emblema (Enenkel, 2018: 18). En la edición impresa se añade un dístico bajo la pictura; los autores de estos versos -advierte Camerario- fueron su sobrino Joaquín Jungermann (1561-1591), estudiante de Medicina con dotes poéticas y artísticas (Tomasi y Willis, 2009: 248-250); su amigo Konrad Rittershausen (1560-1613), profesor de leyes en la Universidad de Aldorf desde 1591; y Luis Camerario, su primogénito (1573-1651) (Schubert, 1955). Así, en la Cent. I (págs. 3r-v) nombra a Joaquín, cuya prematura muerte

\footnotetext{
${ }^{3}$ Omito los autores griegos y latinos, que a menudo cita de segunda mano. Para las fuentes, véanse Papy (2003: 208-210), Antón (2012), Antón y Espinosa (2015: 18-27), Hendrikx $(2017: 186,203,206)$ y Enenkel (2018: 335).
} 


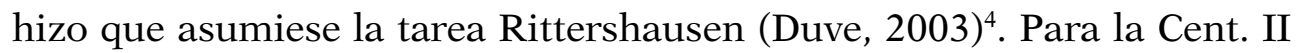
(pág. Cc3r) se valió de su hijo Luis y de algunos amigos (no los identifica), pues confiesa que no es un poeta muy ducho (in hoc genere minus me esse exercitatum ingenue fatebor). En la Cent. III, al final de los Autorum [sic] recentiorum Nomina, nombra a su hijo Luis y a Rittershausen. Los dísticos de la Cent. IV se deben únicamente a su hijo (no consta ningún coautor). Por consiguiente, Luis no solo colaboró en las Cent. II y III, sino que participó activamente en la Cent. IV, hecho que a menudo ha sido soslayado o minimizado por los estudiosos.

Según reza la portada de la Cent. IV, Camerario solo llegó a comenzarla (coepta), si bien en la Cent. II nuestro emblematista da a entender que está pergeñando o elaborando la Cent. IV ${ }^{5}$. De modo que Luis -seguimos en la portada- la concluyó (absoluta) y la publicó años después de morir su padre (post eius mortem). De interés es también la «Epístola Dedicatoria» en la que aporta datos reveladores (págs. 2v-3r):

Ediderat autem ex rei herbariae \& animalium historia Centurias Tres: atque in eo jam erat, ut Quartam etiam ex promisso adornare inciperet. Sed vix rem agressus fuerat, \& in ipso conatus exordio hei Mors invida manus in illum injicit, nobis ac Reip. de cunctis bene merentem eripit.

[«Había publicado (mi padre) las tres centurias de la historia de las plantas y de los animales, y tenía ya la intención de empezar a redactar también la cuarta según había prometido. Pero apenas se había puesto a ello, cuando, en el inicio mismo de la empresa jay! la muerte odiosa se apodera de él y nos arrebata, a mí y a la patria, a quien se comportaba bien con todos»].

\footnotetext{
${ }^{4}$ Entre enero y abril de 1593 trabajaba en los dísticos de la Cent. I (Harms y Hess, 2009: XV).

${ }^{5}$ En la Cent. II, emb. 88, Vincit so[I]lertia vires [«El ingenio vence a la fuerza»], cuyo motivo es la ardilla (sciurus), recuerda lo que dice Opiano $(H .1,340-354)$ del piscis nautilus y agrega: Nec absimilis est natatio piscis Nautili ab eodem copiose descripta in piscatione lib. I de qua, DEO volente, plura in IIII. nostra Centuria de Aquatilibus \& reptilibus dicemus [ Y no es diferente la forma de nadar del pez nautilo, que ese mismo (sc. Opiano) detalladamente describe en el lib. I sobre la pesca; de esa forma de nadar, si Dios quiere, hablaré en extenso en mi Centuria IV sobre los peces y reptiles»].
} 
Líneas más abajo, admite que no es el más indicado para llevar a buen fin esta tarea, porque su temática es la propia de un naturalista, no de un jurista como él:

Vtinam vero supremam huic operi manum imponere illi licuisset. Jam \& prodiret illud profecto multo accuratius, \& eadem esset in hac, quae in prioribus Centuriis ubique pulcritudo \& gratia, max. cum aquatilium \& reptilium historia prorsus sit physica, \& Medici propria. Nunc ego ut cunctanter, \& amicis tandem magis, quam mihi ipse obsequens, accessi ad perficiendum, quod a patre coeptum erat.

[«Pero ojalá se le hubiese permitido dar la última mano a esta obra. Entonces, sin duda, saldría de forma mucho más elaborada y esta centuria tendría la misma belleza y el mismo encanto que muestran por doquier las centurias precedentes, sobre todo porque la historia de los animales acuáticos y reptiles es enteramente física y propia de un médico. Ahora yo, aunque vacilante y, en fin, por complacer más a mis amigos que a mí mismo, accedí a terminar lo que había empezado mi padre»].

Arguye (pág. 3v) que le bastó seguir los pasos de su padre (parentis vestigia) en la recopilación de materiales (in colligendo) y que se dio por satisfecho con haber añadido brevemente (succincte) a las noticias de historia natural algunos datos éticos y, en ocasiones, históricos (physicis ethica, atque interdum historica quaedam). Por ello, es justo reconocer la gran contribución a la Cent. IV del joven Luis: compuso los dísticos que hacen de subscriptio del emblema triplex e ilustró con noticias morales e históricas las zoológicas que había recabado su padre. Un mérito adicional es la dificultad que entrañaba para él, un jurista, ocuparse de los animales acuáticos y de los reptiles, parcela de la historia natural que su padre habría acometido facile et libentissime.

Estas 400 lucubrationes, como define también el autor sus emblemas (Cent. I, pág. A4r), compendian escogidas reflexiones fitológicas (Cent. I) y zoológicas (Cent. II, III y IV), aderezadas con enseñanzas morales, políticas y religiosas (que se condensan en apotegmas, paremias, sentencias y loci communes) y exornadas con interpretaciones simbólicas. Según Enenkel (2018: 313), se trata de una obra singular por la extensión y estructura de la colección, por la riqueza y complejidad de los textos en prosa que exponen las concepciones emblemáticas subyacentes, y por los hechos de historia natural, amén de la calidad de las calcografías del 
pintor y orfebre nuremburgués Johann Ambrosius Siebmacher (Sibmacher) (1561-1611).

\section{EL CAMELLO, LA ANGUILA Y LA SALAMANDRA, SÍMBOLO DE LOS SEDICIOSOS Y AGITADORES}

En este vasto repertorio icónico-literario hay tres emblemas protagonizados por animales tan dispares como el camello, la anguila y la salamandra, cuya asociación pone de realce el propio Camerario. El análisis de esta particular tríada zoológica me llevará a identificar las fuentes que aut aperte aut tacite utiliza el autor y a descodificar el significado simbólico que, en la esfera de las relaciones humanas, le confiere a la rara animalis proprietas ${ }^{6}$.

\subsection{El camello (Cent. II, 15)}

El primer emblema de los tres $\left(\mathrm{n}^{\text {os }} 15-17\right)$ que dedica al camelus ${ }^{7}$ tiene el ambiguo título Turbata delector [«Turbia me complace»] [Fig. 1].

${ }^{6}$ Lo anuncia el título del libro: Exponuntur in hoc libro rariores [... ] animalium proprietates [ «Se exponen en este libro (...) las características más singulares de los animales»].

${ }^{7}$ Le precede el unicornio, monoceros (emb. 12-14) y le siguen la jirafa / camepardalis (emb. 18) y el uro / urus (emb. 19). En Gesner (1551) estos animales van consecutivos, salvo el unicornio (págs. 781-786), pero en un orden diferente: De uro (págs. 157-159), De camepardali (págs. 160-162), De camelo (págs. 162-171) y De camelo dromade (págs. 171 173). 

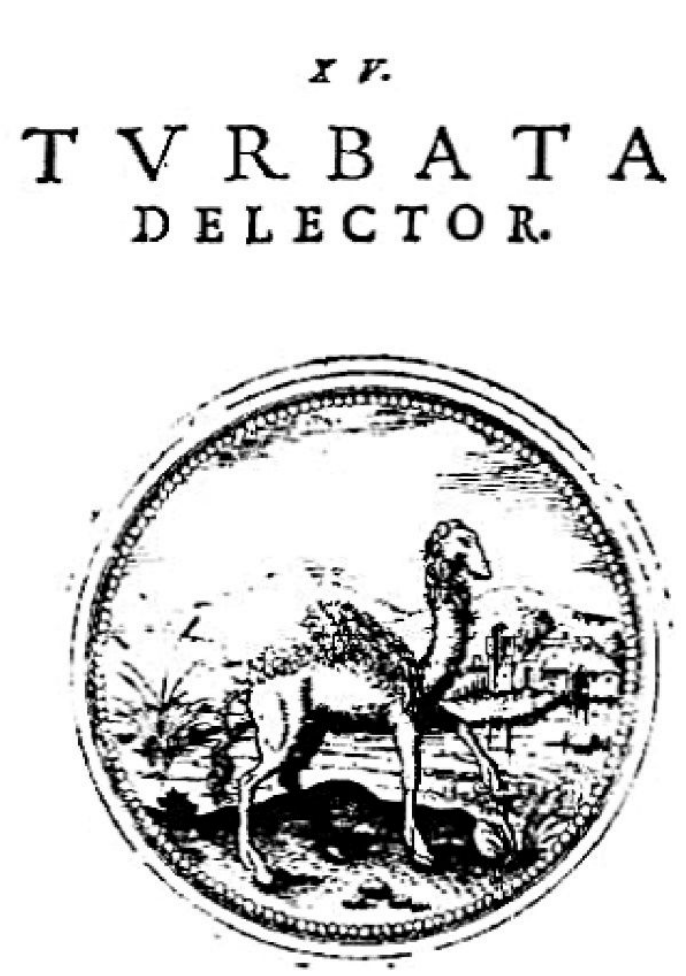

\section{Turbat aguam fatiens cum valt baurire Camelus, sicpacem ex bellis, qui lucra fadafitit.}

Figura 1: Camerario (1595, Cent. II, emb. 15). Fuente: URL: https://archive.org. No copyright.

En el dístico, que -como ya advertí- no es obra de Camerario, el hexámetro describe el modo de beber del camello (la res significans), si bien en la res picta figura un dromedario (camelus dromedarius o arabicus) ${ }^{8}$; en el pentámetro se explicita el símil (la res significata):

${ }^{8} \mathrm{La}$ imagen coincide con la que ofrece Gesner (1551: 172) del dromedario (camelus

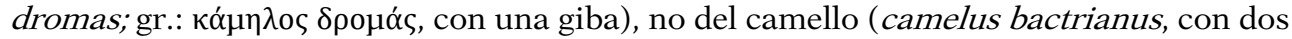
gibas) (1551: 163). Henkel y Schöne (2013: 425-426) recogen otros emblemas con el 
Turbat aquam sitiens cum vult haurire Camelus, sic pacem ex bellis, qui lucra foeda sitit.

[«Enturbia el agua el camello sediento cuando quiere beber. Así obra quien ansía la paz como una cruel ganancia obtenida de la guerra»].

El comentario, ceñido al espacio de una página en $4^{\circ}$, se divide en dos partes, una física y otra moral. La física empieza con una breve descripción del cuadrúpedo y su rara proprietas, es decir, su modo de beber. Plinio es aquí su principal referente ${ }^{9}$, mas no el único:

Camelorum duo genera reperiuntur apud veteres, praesertim Aristotelem II. de historia Animalium [HA 2, 1], \& Plinium lib. VIII, cap. XVIII [nat. 8, 26, 67]. Bactrianum nimirum sive Asiaticum, \& Africanum, illi bina, huic singula tubera in dorso habent. Hoc animal (ut Plinii verbis utar [nat. 8, 26, 68]) sitim \& quatriduo tolerat, impleturque cum bibendi occasio est \& in praeteritum \& in futurum, obturbata proculcatione prius aqua, aliter potu non gaudet. Quam proprietatem Aelianus ${ }^{10}[N A 17,7]$ quoque Elephanti ascribit, cui aquam claram \& nitidam esse inimicissimam ait.

[ «Se constatan dos clases de camellos en los autores antiguos, sobre todo en Aristóteles, lib. II de la Historia de los animales (HA 2, 1), y en Plinio, lib. VIII, cap. XVIII (nat. 8, 26, 67), es decir, el bactriano o asiático y el africano; aquel tiene dos jorobas en el lomo, y este una. Este animal (por usar las palabras de Plinio) soporta la sed durante cuatro días y, cuando tiene ocasión de beber, se sacia para cubrir las necesidades pasadas y las futuras, enturbiando antes el agua con la pezuña; de otro modo, no disfruta bebiendo. Eliano ( $N A$ 17,7) también atribuye esta propiedad al elefante, al que -dice- le desagrada el agua clara y diáfana»].

motivo del camello («Kamel»), aunque las pinturas, cuando las incluyen, muestran un dromedario; este emblema de Camerario, pero sin grabado, está en la col. 426.

${ }^{9}$ Plinio desempeñó un importante papel en los emblemas zoológicos de Camerario, hasta el punto de que Enenkel (2018: 319-321) ve en él un Plinius emblematicus.

${ }^{10}$ Camerario parece seguir la versión latina de Eliano (1565: 474) que hizo Gilles, De pastu \& potione elephanti, cap. VII: Clarae aquae potio elephanto inimicissima est, turbulentam \& sordidam suauissime bibit, ac si ad flumen aut ad lacum accesserit, non priusquam coenum pedibus perturbarit, \& pulchritudinem aquae deformarit ad hauriendam aquam incumbit. ["Beber agua limpia es muy desagradable para el elefante; bebe más gustosamente agua turbia y embarrada, y si se aproxima a un río o a un lago, no se inclina a beber antes de ensuciar la diafanidad del agua revolviéndola con sus patas»]. 
El autor, que a veces toma las citas clásicas de fuentes secundarias, aquí lo hace de Gesner, quien en el Lib. I de la Historia animalium ${ }^{11}$ distingue dos tipos de camellos, los bactrianos y los arábigos, y explica su forma de beber acudiendo a Aristóteles, en la versión latina del humanista griego Theodorus Gaza ${ }^{12}$.

A la vista de las fuentes clásicas que aduce, es perceptible que Camerario utiliza el término camelus no para designar el camello como especie, sino como género, al que pertenecen el camello bactriano o asiático (camelus bactrianus, nativo de Asia Central) y el dromedario (camelus dromedarius, originario de Arabia y extendido por África), aunque en el grabado se represente únicamente a este último.

Tras la parte zoológica, viene la parte simbólica, que es de este tenor:

Eundem profecto admodum homines inquieti, ac turbulenti omnia propter suam utilitatem pervertunt, tranquillitatis publicae hostes (quorum utinam hodie non tantus extaret numerus) qui omnia sua consilia et cogitata eo dirigere student, ut alios inter se committant, ac bella non necessaria excitent.

[«Ciertamente, de igual modo, los agitadores y revoltosos pervierten todo por interés particular; son enemigos de la paz pública (¡ojalá no hubiera hoy tan gran número de estos!), que se afanan en dirigir todos sus planes y designios a enfrentar a otros entre sí y provocar guerras innecesarias»].

Nuestro emblematista amplía la esfera moral con un ejemplo de su propia época: Et scimus nostris temporibus callidum quendam ducem

${ }^{11}$ Gesner (1551: 165C): Cameli \& equi turbulentam \& crassam aquam suauius bibunt, quippe quae ne ex fluuio quidem prius hauriant, quam pede inturbent. Possunt uel ad quatuor dies tolerare sine potu, mox bibunt quam multum, Arist. Sitim \& quatriduo tolerant: implentur cum bibendi occasio est, \& in praeteritum \& in futurum, obturbata conculcatione prius aqua: aliter potu non gaudent, Plinius. [«Los camellos y caballos beben con más gusto agua revuelta y fangosa, pues estos animales ni siquiera beben agua corriente antes de enturbiarla con la pata. Incluso logran pasar hasta cuatro días sin beber y luego beben todo lo que pueden. Arist. $(H A 8,8)$. Soportan la sed durante cuatro días y, cuando tienen ocasión de beber, se sacian para cubrir las necesidades pasadas y las futuras, una vez que han enturbiado antes el agua con la pezuña; de otro modo, no se complacen en beber. Plinio (nat. 2, 26, 68)»].

${ }^{12}$ Gaza (1524: 75v): [...] at equi, vt cameli, turbulentam \& crassam suauius bibunt, quippe que ne ex fluuio quidem prius hauriant, q[uam] pede inturbent. possunt vel ad quatuor dies tolerare sine potu mox bibunt, q[uam] multum. 
militarem crebro solitum esse dicere, non nisi aqua bene turbata piscationem esse uberem [ "Sabemos que en nuestro tiempo un sagaz condotiero solía repetir que no se obtiene una pesca abundante si antes no se revuelve bien el agua»]. La expresión callidus... militaris designa al condottiero Gentile Virginio Orsini, señor de Bracciano (ca. 1434-1497) (Camilli, 2013). El origen de su divisa [Fig. 2] lo explica el autor con Paolo Giovio (1559: 53-55) ${ }^{13}$, pero adaptando su relato:

De hoc apud Jovium talis legitur historia. Virginius Vrsinus strenuus alioqui bellator, contra aliorum sententiam, etiam suorum gentilium, quo tempore quasi universa Italia contra Gallos conspiraverat, nihilo tamen minus ipse castra Gallica sequi maluit. Atque ideo hoc Symbolo usus est cum Gallica sententia, Il me plait la tovrble [sic], mihi turbida placet, sed parum extitit ipsius conatus felix, nam in isto bello gravissimo obsessus Atellae, in hostium potestatem pervenit, \& tandem in carcere Castelli de Ovo Neapoli justas suae temeritatis poenas luens, misere interiit.

[ «Sobre esto se lee en Giovio una historia semejante: Virginio Orsini, por lo demás un aguerrido condotiero, en contra de la opinión de otros, incluso de sus familiares, en la época en que casi toda Italia conspiraba contra los franceses, él prefirió no obstante secundar el bando francés. Y por eso usó esta divisa con la sentencia gala: Me agrada la confusión. Pero duró poco su feliz intento, pues, cuando en esa sanguinaria guerra estaba asediado en Atela, cayó en poder de los enemigos y al final murió miserablemente en la cárcel del Castel dell'Ovo, en Nápoles, expiando la culpa de su temeridad»].

${ }^{13}$ Cito por la ed. de Lyon, la primera con grabados (el dibujo representa un dromedario): "Ma esso, indurato da una fatale ostinatione, andò col seguito di molti Capitani della fattion sua contra il Re Ferrandino, dicendo a chi lo consigliava, e fra gli altri agli huomini del Papa, del Duca Lodovico e de' Signori Vinitiani che gli proponevano e mostravano i pericoli ne' quali si metteva et i chiari premii che dall' altra parte se gli offerivano: Io son simile al Camelo, il quale per natura, arrivando a un fonte chiaro, non beve di quell' acqua se prima calpestrandola non la fa torbida. E per questo portò un Camelo che intorbidava una fonte, inchinandosi per bere, con questo motto Francese: IL ME PLAIT LA TROUBLE. Ma certo il suo tristo consiglio hebbe pessimo fine, perché, superato in quella guerra, assediato in Atella e preso, morì nella prigione del Castel dell' Uovo, e così portò la pena della sua perversa opinione». La ed. princeps (1555: 56-57, empresa de Orsini) fue publicada póstumamente (Arbizzoni, 2007: 9-10). 


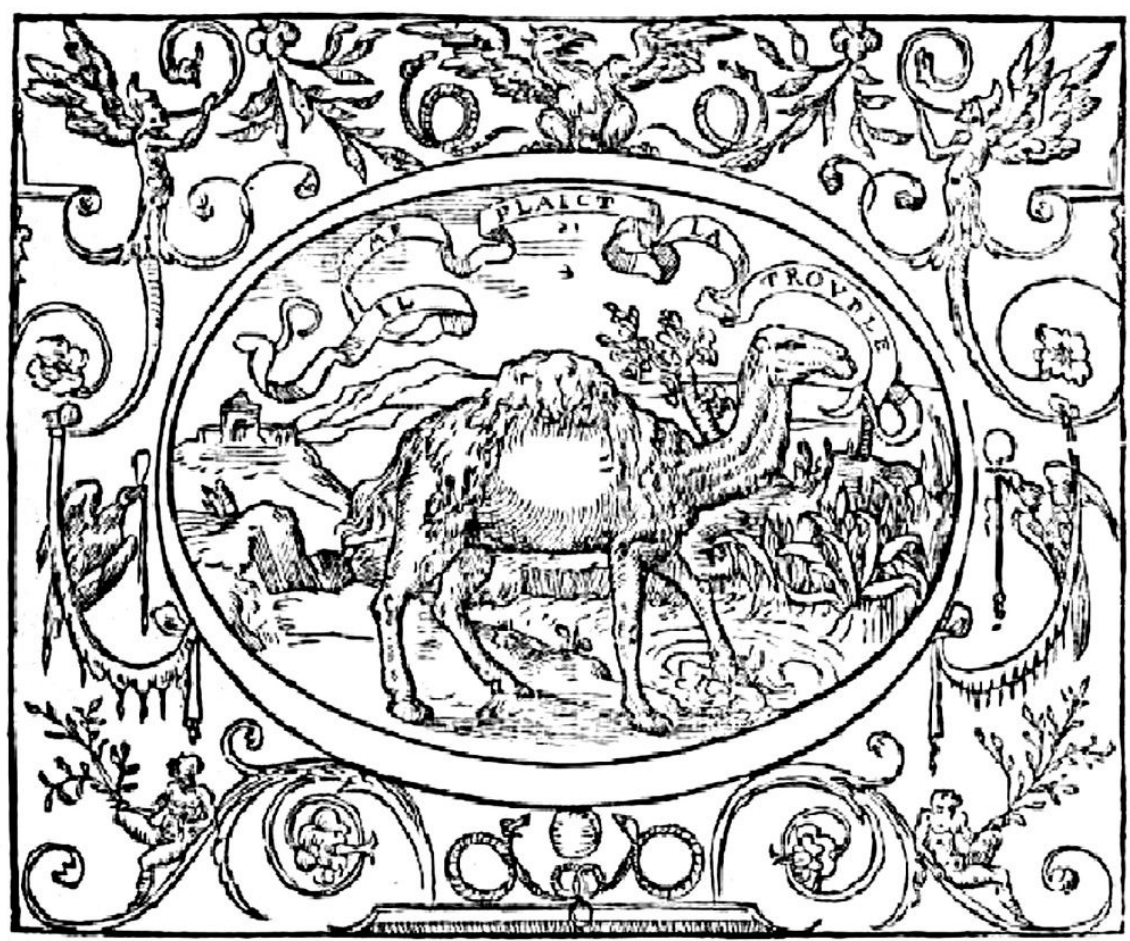

Figura 2: Giovio (1559: 53). Empresa de Orsini.

URL: https://archive.org. No copyright.

Este emblema tiene su equivalente en el specimen manuscrito arriba citado (Harms y Hess, 2009: 502-503), lo que permite conocer la primigenia redacción de Camerario: la pictura muestra dentro de un círculo un camélido (un dromedario) bebiendo; en el comentario se expone sin más preámbulos la rara proprietas del ungulado: Camelus non limpida sed commota aqua delectatur, quare priusque illam bibat, pedibus solet turbare [ El camello no gusta del agua limpia sino sucia, por lo que antes de beberla suele enturbiarla con las patas»]. El significado simbólico lo explica el autor en términos mucho más escuetos, sin nombrar a Giovio y aportando una interpretación religiosa de cuño luterano, que luego eliminó en la edición impresa:

Imago est hominum inquietorum, qui ut suis commodis melius frui queant, saepe homines alioqui pacis amantes inter se committunt ac non 
necessaria bella excitant. Potest etiam illis attribui, qui humanis traditionibus $^{14}$ veram et sinceram doctrinam perturbant. Gallicum est / prouerbium: IL ME PLAIT LA TOVRBLE[sic].

[«Imagen es de los agitadores, los cuales, para poder disfrutar mejor de sus ganancias, a menudo enfrentan entre sí a hombres por lo demás amantes de la paz y provocan guerras innecesarias. También cabe atribuirse a los que tergiversan la auténtica y verdadera doctrina con tradiciones humanas. Galo es el proverbio: La agitación me complace»].

Por lo demás, la vulgatissima divisa de Orsini la transmiten (con un dromedario en el grabado), v. gr., Battista Pittoni (1562: 17), Giulio Cesare Capaccio (1592: II, 44, fol. 90r) ${ }^{15}$, Guillaume de La Perrière (1544: 69) y Juan de Horozco (1589: III, 13).

\subsection{La anguila (Cent. IV, 45)}

Este pez anguiliforme es el motivo del emb. 45, Turbato flumine capta [«En río revuelto es capturada»] ${ }^{16}$ [Fig. 3].

${ }^{14}$ Aquí con traditiones se hace referencia a los ritos o ceremonias instituidos por los hombres y que contradicen la ley divina; véase Vulg. Matth. 15,8-9: Populus hic labiis me honorat, cor autem eorum longe est a me. / Sine causa autem colunt me docentes doctrinas, et mandata hominum [ «Este pueblo me honra solo de palabra, pero su corazón está lejos de mí; en vano me rinden culto, enseñando doctrinas y mandamientos de hombres»]; Lutero (1525: 4v) en De traditionibus evoca los versículos de Mateo: Populus, inquit, iste labijs solu[m] me colit, eoru[m] aute[m] cor longe a me dissitu[m] est. Verum frustra me colunt. Quandoquidem humanas doctrinas et traditiones doce[n]t.

${ }^{15}$ La empresa II, 44 carece de imagen; pero un dromedario ilustra la empresa II, 42, fol. $89 r$ (en la filacteria que hay en el interior del grabado se lee Parturient montes).

${ }^{16}$ Está situada entre otro pez anguiliforme, la morena / muraena (emb. 43-44) y un pez perciforme, la salpa / salpa (emb. 46). En Gesner (1558) varía el orden: De anguillis (pág. 45), De muraena (págs. 678-690), De salpa (págs. 979-983). 


\section{TVRBA T O FL V MINE CAP T A.}

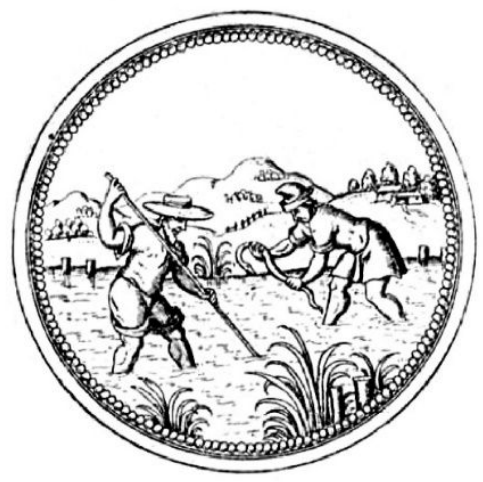

Turbato anguille sapiuntur flumine. fic res Turbarc is patria fedisiogus amat.

Figura 3: Camerario (1604 [1605], Cent. IV, emb. 45).

URL: https://archive.org. No copyright.

La res significans, esto es, la técnica de pescar anguilas, la reproduce el dibujo y se menciona en el epigrama, donde se compara a los pescadores de anguilas (anguillarum captatores) $)^{17}$ con los amigos de sediciones (la res significata $)^{18}$ :

Turbato anguillae capiuntur flumine, sic res

Turbare in patria seditiosus amat.

[ «Se capturan las anguilas en río revuelto. Así, el sedicioso desea perturbar la situación de la patria»].

${ }^{17}$ Sobre este motivo en obras del siglo XVI de tema zoológico, paremiológico y simbólico, véase Antón 2021: 258-263.

${ }^{18}$ De ahí los refranes «Pescar en río revuelto» $\mathrm{y}$ "A río revuelto ganancia de pescadores», con equivalencia en muchas otras lenguas (Flonta, 2012: 1008). 
Camerario inicia el comentario informando de que las anguilas se capturan en aguas muy revueltas y limosas (maximis turbatis \& limosis aquis), según transmiten las fuentes griegas (Aristóteles [HA 592a], Ateneo de Naucratis [7, 298B-C], Clemente de Alejandría [Strom. 7, 16, 99, 1-2]) y enseña la experiencia (docet experientia). Luego, cita el Hexaeme-

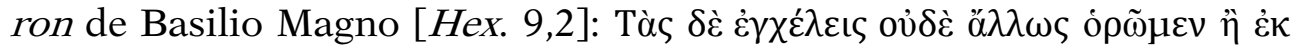

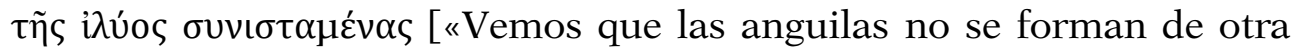
manera que de barro»]. A partir de este locus de Basilio y la nota de Ateneo (Ex quo loco \& Athen. Indicatione) introduce un breve apunte etimológico que le facilitó el humanista luterano David Hoeschelius (Höschel, 1556-1617) ${ }^{19}$, hombre eruditísimo (doctissimus vir) y amigo suyo (amicus noster), que con tino (certe) enmendó al etimologista, pues este

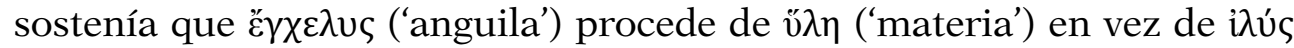

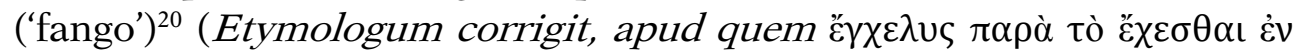

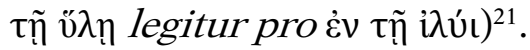

A propósito de los anguillarum venatores, trae a colación el emblema de Alciato In divites publico malo [«Sobre los que se enriquecen con la desgracia pública»] ${ }^{22}$ [Fig. 4], de argumento similar al suyo y su modelo iconográfico:

Symbolum autem hoc vel ex Aesopi apologo ${ }^{23}$, vel ex Aristophanis Equitibus [Eq. 864] ${ }^{24}$ rem in turbulentos cives, qui ex Reip. motu ditescere, \& saepe, ut Tacitus loquitur [hist. 1, 53, 2], privata vulnera reip. malis

${ }^{19}$ Camerario (Cent. II, 58) califica a Höschel de amicus meus singularis (Smith, 2017: 156) y recuerda su edición grecolatina de los Hieroglyphica (1595) de Horapolo, publicada poco ha (nuper... editis), obra que también utiliza aquí, pero sin mencionarla (vid. infra). Además, Höschel mantuvo correspondencia con nuestro autor y con su hermano menor Felipe (1537-1624) (Kohlndorfer-Fries, 2009: 167; Lenk, 1972), renombrado jurista, autor de la famosa miscelánea Operae horarum succisivarum (Camerario, 1591).

${ }^{20}$ Se supone que $\tilde{\gamma} \gamma \chi \varepsilon \lambda \nu \varsigma$ resulta del cruce del término ह̌㐅ıৎ ('serpiente') y una palabra como el lat. anguis (de ahí anguilla). No puede reconstruirse una protoforma indoeuropea. He consultado (s. v. ह̌ $\gamma \chi \varepsilon \lambda v \varsigma$ ) Boisacq (1916), Chantraine (1970) y Beekes (2010).

${ }^{21}$ La enmienda está en Höschel (1595: 209, cap. 102, है $\left.\gamma \chi \varepsilon \lambda u v\right)$.

${ }^{22}$ Este emblema apareció por primera vez en la edición aldina (Alciato, 1546: 3r).

${ }^{23}$ Véase Chambry (1927: 27). La fábula en cuestión (no se menciona la anguila) es "El pescador que batía el agua», cuyo epimythion alude a los demagogos que, para su lucro personal, siembran discordias en la patria. Para el luterano Camerario las fábulas esópicas serían muy familiares, pues Lutero era un entusiasta de Esopo, al que consideraba un excelente vehículo pedagógico, el segundo después de la Biblia para instruir moralmente a los jóvenes (Springer, 2011: 35).

${ }^{24}$ Sobre este popular locus aristofánico, véase Antón 2021: 259. 
operire statuunt, detorquentis, desumpsit Alciatus, cujus elegantiss. in divites pub. malo Epigramma legitur Embl. LXXXVIII.

[«En efecto, de la fábula de Esopo o de Los Caballeros de Aristófanes (Eq. 864), quien transmuta el motivo aplicándolo a los ciudadanos turbulentos que se enriquecen con las discordias civiles y que a menudo, como expone Tácito (hist. 1, 53, 2), "deciden encubrir los desastres privados con las calamidades públicas", tomó este símbolo Alciato, cuyo elegantísimo epigrama Sobre los que se enriquecen con la desgracia pública se lee en el emblema LXXXVIII»].

In disites publico malo .

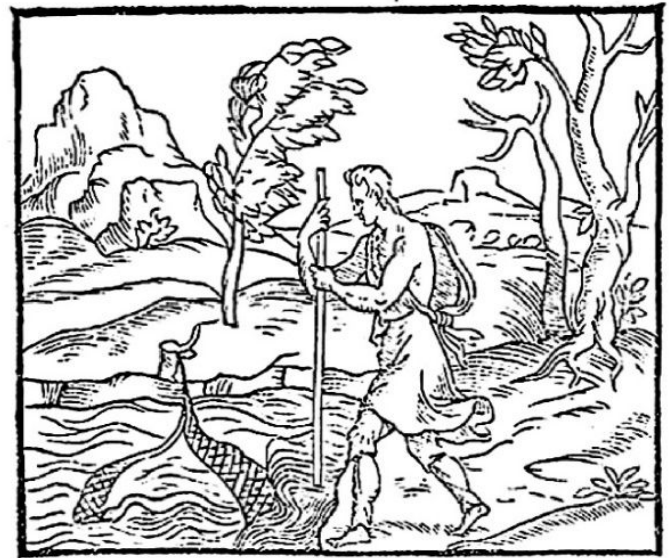

Anguillas quifguis captat, fi limpida uerrat Flumina, $f i$ illimes aufit adire licus, Cafjus erit, lidet'́; operam . multum exciter ergo si crete, ef witreas pa!mula turbet aquas, Diues erit. fic ïs res publica turbida lucro eft, Quipace, arctati legibus, efurimt.

\section{A iii}

Figura 4: Alciato (1546: 3r). URL: https://archive.org. No copyright.

A esos divites -continúa- se refiere Cicerón en el segundo discurso contra Catilina [Cat. 2, 9]: Honores quos quieta rep. desperant, turbata consequi se posse arbitrantur [«Los honores que no esperan conseguir 
con la república tranquila, creen que pueden alcanzarlos con ella re-

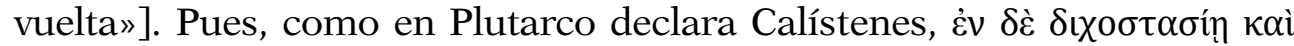

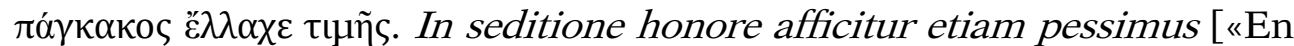
una guerra civil incluso el más depravado recibe honores» $]^{25}$. Semejante a

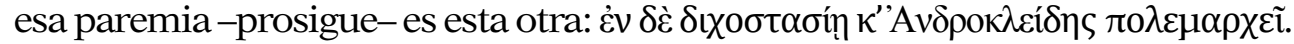
Seditione orta dux est etiam Androclides [ «En una sedición, incluso Andróclides es general»], que transmiten la Suda ${ }^{26}$, Diogeniano $[4,55]$ y Plutarco [Nic. 2, 3]. Estas tres referencias están en el adagio erasmiano In seditione, vel Androclides belli ducem agit ${ }^{27}$ [ «En una sedición, incluso Andróclides dirige la guerra»], de donde con probabilidad las extrajo nuestro emblematista. A esto mismo cree que se refieren otros proverbios similares (similia proverbia alia), sobre todo 'Е $\gamma \chi \varepsilon ́ \lambda \varepsilon\llcorner\varsigma ~ \theta \eta \rho \tilde{\alpha} \sigma \theta \alpha$. Anguillas captare $^{28}$. Indica que este emblema debe vincularse al 15 de la Cent. II y al 70 de la Cent. IV, formando los tres una unidad. Por último, Camerario, con loci de Plutarco y de Justino, recuerda la táctica empleada por Filipo de Macedonia para hacerse con el poder:

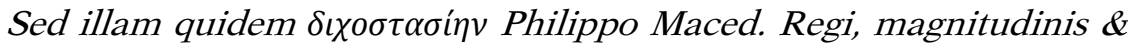
potentiae occasionem \& causam extitisse, ajebat Callisthenes [Plu. Alex. 53, 5]: Qui, ut Iustinus [8, 1] inquit, veluti e specula quadam libertati omnium (civitatum Graeciae puta) insidiatus, dum contentiones civitatum alit, auxilium inferioribus ferendo, victos pariter victoresque subire regiam servitutem coegit.

[«Pero decía Calístenes (Plu. Alex. 53, 5) que sin duda para Filipo de Macedonia aquella sedición había sido la oportuna causa de su grandioso poder. Este (sc. Filipo), según afirma Justino $(8,1)$, acechando como desde una atalaya la libertad de todos (entiéndase, de las ciudades griegas), mientras alimentaba la discordia entre las ciudades prestando ayuda a las más débiles, obligó a vencedores y vencidos a padecer su despótica esclavitud»].

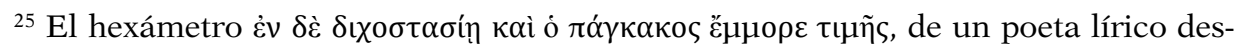

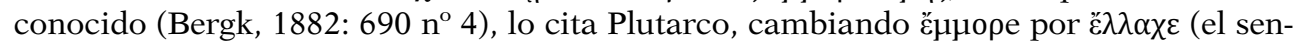

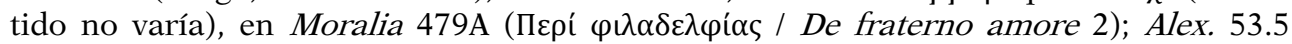
(695E); Nic. 11.3 (530D) y la Lysandri cum Sylla comparatio 1 (475F) (Antón, 2021: 264).

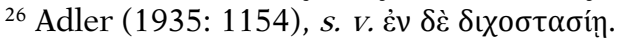

${ }^{27}$ Erasmo, adag. II.11.91 (Saladin, 2011: II, $136 \mathrm{n}^{\circ} 1191$ ).

${ }^{28}$ Erasmo, adag. III.6.79 (Saladin, 2011: III, 273 n 2579); véase Antón (2021: 260). 


\subsection{La salamandra (Cent. $I V, 70)$}

El emblema titulado Coelo turbato alacrior [ «Con tiempo revuelto soy más feliz»] [Fig. 5] lo protagoniza un anfibio: la salamandra ${ }^{29}$. Sin embargo, no se la nombra en la inscriptio ni tampoco en la subscriptio, que dice así:

Sunt pluviae mihi vita, necem sed Sirius ${ }^{30}$ affert, In pace \& languent, quos fera bella fovent.

[«Las lluvias me dan la vida, en cambio Sirio me causa la muerte. En la paz languidecen esos a los que las crueles guerras alientan»].
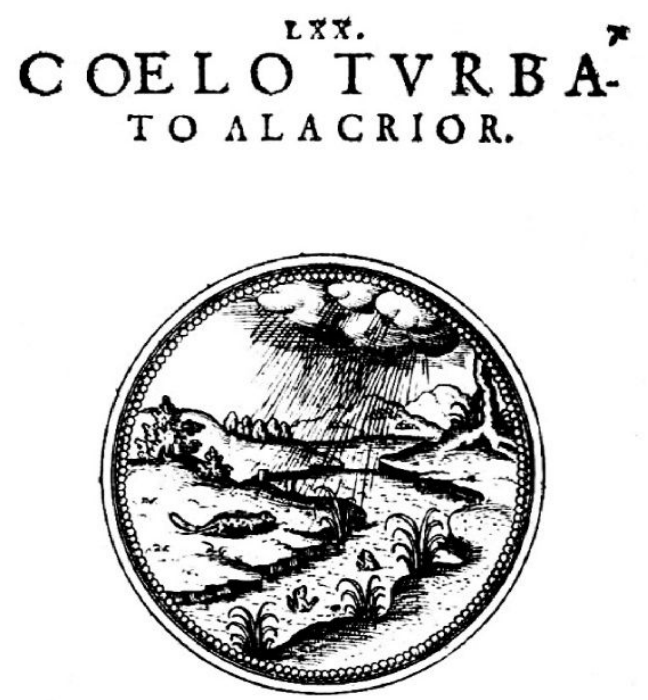

\footnotetext{
Snns pluvie milsi vita, neeten fed Sirius affert ; In pace do Linguent, quos fera bella fovers.
}

Figura 5: Camerario (1604 [1605], Cent. IV, emb. 70). URL: https://archive.org. No copyright.

${ }^{29}$ Va precedida por la popular salamandra ígnea (emb. 69) y seguida de la rana (emb. 71-73). Gesner (1554) cambia el orden: De rana (págs. 41-74) y De salamandra (págs. 7483), con referencia a la salamandra ígnea (76C). Sobre el simbolismo de la salamandra, véase García Arranz (1990), Biederbick (2017: 249-303) y Antón (2021: 253-258).

${ }^{30}$ Sirius, en la constelación Can Mayor (Canis maior / Canicula), es la estrella más brillante del cielo nocturno; aquí designa la época más calurosa del año, los llamados dies caniculares, desde mediados de julio a mediados de agosto. 
Es el propio caudado el que, mediante la figura retórica de la prosopopeya, revela en el hexámetro su rara proprietas, que constituye la res significans, en tanto que el pentámetro alberga la res significata. En lo tocante a la res picta, en tierra hay una bestiola y otras dos que, bajo la lluvia, emergen de un riachuelo. Por lo tanto, el dibujo reproduce la res significans, pero solo parcialmente: la salamandra disfruta de la tempestad, a lo que alude el título (Coelo turbato alacrior) y la mitad del primer verso (Sunt pluviae mihi vita), y se excluye la escena en que el calor (Sirio o la Canícula) la obliga a ocultarse.

En el comentario, el autor descubre la identidad del animal, la salamandra aquatilis, cuya verdadera descripción quiere ofrecer enmendando la del médico y naturalista P. Andrea Mattioli ${ }^{31}$ :

Salamandrae aquatilis figuram veram exprimi studuimus, cum falsa Matthioli, \& bestiola illa a multis cum Cor[d]ylo \& Scinco ${ }^{32}$ fere

${ }^{31}$ Mattioli (1554: 197), Lib. II, cap. 56, $\Sigma \alpha \lambda \alpha \mu \alpha \alpha$ $\nu \delta \rho \alpha$. Salamandra: Salamandra corporis magnitudine, formaque lacerto similis est; verum capitis, ac ventris crassitudine excellit, breviore tamen constat cauda. Illa etsi altioribus nitatur cruribus; ad gressum tamen ignavior est, hic vero contra agilis, celerque conspicitur. Color illi niger, luteis non minimis insectus maculis, quadam laevitate pellucidus. [«La salamandra por el tamaño y la forma del cuerpo es similar al lagarto, pero se distingue por el grosor de su cabeza y del vientre; no obstante, se sabe que la cola es más corta. Aunque aquella se sostiene sobre patas más largas, sin embargo, avanza con más lentitud: este, por el contario, parece más ágil y rápido»]. Y al final le dedica unas líneas a la salamandra aquatica (Mattioli, 1554: 198): Est et Salamandrae aquaticum genus Utinensibus frequentissimum, capite terrestribus breviore rotundioreque, cauda anguillarum modo, nigro undique dorso, ventre autem rufescente, luteis maculis resperso, horrendo aspectu, aeque atque terrestre ["Existe también una clase acuática de salamandra muy común en la región de Udine, de cabeza más pequeña y redonda que las terrestres, cola a modo de las anguilas y lomo negro todo él; en cambio su vientre es rojo y salpicado de manchas amarillas y su aspecto horrible, al igual que la terrestre»]. Esta descripción, que denuncia como falsa Camerario, se ajusta a la del triturus carnifex (tritón crestado italiano), que se distribuye por Italia, una amplia parte de Austria y una pequeña área del sur de Suiza (Sparreboom, 2014: 340-342); por lo tanto, sería fácil verlo en la zona de Udine (Utinum). Véase Bossuet (1558: 128, De Salamandra aquatili).

32 Gesner (1558: 967-968, De salamandra aquatili. Rondeletius), al tratar de la salamandra acuática siguiendo a G. Rondelet, la describe como un cuadrúpedo que, a semejanza de las serpientes (serpentum ritu), habita en las orillas de las fuentes y de las charcas (in fontibus \& stagnorum ripis habitans); a menudo se desplaza fuera del agua y se pone al sol; luego, no de un salto, sino a la carrera, se mete en el agua. Advierte que ambos caudados, el terrestre y el acuático, se designan con el mismo nombre ('salamandra') en griego, en latín y en las lenguas romances. No ignora que es un animal anfibio (amphibium) o, si se prefiere, solo acuático, y que se confunde con el cordilo y el escinco. Gesner se ocupa de este en el Lib. I (1551: 21-27, De scinco quem \& crocusdylum terrestrem 
confundatur. Sed ne hîc sculptor omne punctum tulit ${ }^{3}$. Lacertum (cujus speciem Theophrastus [Ign. 60] eam videtur facere) refert propemodum corporis specie, caput maculis albis refertum habet, \& in dorso pinnulam rectam per totum, oris rictum ranae similem, caudam, ut in Cobitide fluviatili $^{34}$ vel potius in anguilla cernimus, nonnihil latam.

[«He querido que se conozca la verdadera imagen de la salamandra acuática, pues es falsa la de Mattioli y, de ordinario, muchos confunden ese animalillo con el cordilo y el escinco. Pero resulta que aquí el grabador no acertó. Por la forma del cuerpo remeda al lagarto (parece que Teofrasto [Ign. 60] la considera de la especie de este); tiene la cabeza repleta de manchas blancas y una aleta recta a lo largo de todo el lomo; la boca, similar a la de la rana; la cola, como vemos en la cobítide fluvial o mejor en la anguila, algo larga»].

Para lo tocante al hábitat y al comportamiento, recurre a Plinio [nat. 10, 86, 188]: Degit in fluminibus \& stagnorum ripis, \& per fulgetra \& tempestates caput exerit. Hinc Plinius scribit, nunquam nisi magnis imbribus provenire, \& serenitate deficere [«Habita en los ríos y en las orillas de las charcas, y se deja ver durante los tormentosos aguaceros. Por eso escribe Plinio que nunca sale a no ser con copiosas lluvias, y con tiempo despejado desaparece»].

La rara proprietas de este urodelo, que sale cuando llueve y se oculta cuando brilla el sol, podría valer tanto para la salamandra común, terrestre, forestal o ígnea (salamandra salamandra) (Velo-Antón y Buckley, 2015), como para la salamandra acuática o tritón (triturus) (Sparreboom, 2014: 343-344), ambos de la familia de los salamándridos (salamandridae). Huelga decir que pecaría de poco o de nulo rigor científico si me aventurase a identificar el tipo de caudado a partir de una pictura tan desafortunada (no se aprecian bien los rasgos morfológicos de la bestiola, que se asemeja más a un pequeño mamífero que a un anfibio), de ahí que

uocant [ «Del escinco al que llaman también cocodrilo terrestre»], y del otro en el Lib. IV

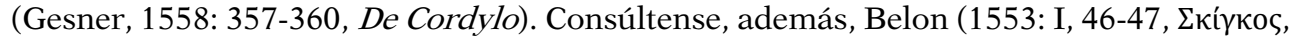

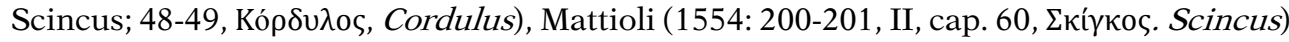
y Bossuet (1558: 129, De Scinco; 131, De Cordylo).

${ }^{33}$ Reminiscencia horaciana (ars 343).

${ }^{34}$ Belon (1553: 214), Gesner (1558: 479, de cobitide fluviatili). 
el emblematista diga que el grabador (sculptor) se equivocó ${ }^{35}$. Por el contrario, el comentario aporta información más sustanciosa y certera. En efecto, confirman que se trata del tritón, y en concreto del tritón crestado (triturus cristatus), no tanto el adjetivo aquatilis con que califica Camerario a su salamandra ${ }^{36}$, como el que le atribuya una aleta recta a lo largo de todo el lomo (in dorso pinnulam rectam per totum), una cabeza repleta de manchas blancas (caput maculis albis refertum) y una cola no muy larga (caudam...nonnihil latam) ${ }^{37}$. Por consiguiente, si se tienen en cuenta las diferentes clases de tritones y su distribución en el continente europeo (Sparreboom, 2014: 340-356), cabría conjeturar que Camerario y Mattioli describen dos tipos diferentes de tritones: el primero, el triturus cristatus o tritón crestado del norte, y el segundo, el triturus carnifex o tritón crestado italiano, de manera que el médico italiano no andaba tan errado como aseveraba su colega alemán.

Camerario, tras esta primera sección zoológica, enuncia el simbolismo del animal refiriéndolo al comportamiento humano: Eodem plane modo obscuri saepe homines, \& quibus si in pace domi vivendum esset, ne panis quidem ad victum suppeteret, per tumultus \& bella emergunt, $\&$ ad max. cum opes tum dignitates perveniunt [ Exactamente del mismo modo, a menudo los hombres del vulgo y los que, si hubieran de vivir en paz en casa, ni siquiera tendrían un mendrugo de pan que comer, salen durante los tumultos y las guerras, y se hacen tanto con las riquezas como con los honores»]. Esta interpretación política del caudado tiene su

${ }^{35}$ No faltaban autores que, como Camerario, se quejaban de que el encargado de diseñar los dibujos no siempre ofrecía la imagen real de algunos animales, ya porque fueran desconocidos para él, ya porque copiara las figuras de fuentes poco fiables. Así, Gesner (1554: 74) incluye una imagen falsa de la salamandra, que no obstante decidió utilizar en la $2^{\mathrm{a}}$ ed. de los Icones (Gesner, 1560: 119) junto con la verdadera (Kusukawa, 2010: 325-327).

${ }^{36} \mathrm{Y}$ eso, porque también frecuentan el agua para la reproducción las poblaciones ovíparas (no las vivíparas) de la salamandra común (Velo Antón y Buckley, 2015). Para García Arranz (1990: 63) esta es la "salamandra acuática», pero no entra en consideraciones relativas a su morfología.

${ }^{37}$ Las características morfológicas del urodelo coinciden con las del triton cristatus, que ocupa el rango más amplio de la especie Triturus y se distribuye por el centro, norte y este de Europa (Sparreboom, 2014: 342; 344-345), área que incluye el país de nuestro emblematista. 
origen en el Parabolarum, siue Similium Liber (1514) de Erasmo ${ }^{38}$, en quien se inspiraron asimismo dos célebres juristas y emblematistas franceses del siglo XVI: Pierre Coustau y Denis Lebey ${ }^{39}$.

El primero, en Pegma cum narrationibus philosophicis (Coustau, 1555: 95-97), compuso el pegma titulado Ad salamandram, y subtitulado In milites [Fig. 6], donde equipara la salamandra a los soldados que, por interés pecuniario, hacen de la guerra su modus vivendi (Antón, 2021: 257).

A Lebey debo dedicarle mayor atención, porque en el emb. XXIII, In Cleones nostri saeculi, qui nisi turbatis rebus laterent [ «Sobre los Cleones de nuestro tiempo, que permanecen ocultos a no ser que haya disturbios» $]^{40}$ [Fig. 7], representa un motivo y un argumento afines a los del emblema de Camerario.

${ }^{38}$ Margolin (1975: 294): Salamandra non nisi magnis hymbribus prouenit, serenitate deficit: ita quidam non apparent, nisi statu ciuitatis bello aut seditione turbato, iidem rebus pace compositis emoriuntur. Sobre esta fuente, vid. Antón (2021: 257).

${ }^{39}$ Henkel y Schöne (2013: 736) agrupan estos tres emblemas (de Coustau, Lebey y Camerario) bajo el epígrafe "Wassersalamander», y los secunda García Arranz (1990: 6364). Tal clasificación, a mi juicio, responde más a la analogía de los argumentos que al tipo de caudado en sí, pues los emblematistas franceses solo hablan de salamandra, nunca de salamandra acuática, y no la asocian con el agua. En el dibujo de Coustau la salamandra está en un paisaje seco (el arco del fondo parece más un motivo ornamental que un puente) y su aspecto se adecua al de la salamandra terrestre. En cuanto al emblema de Lebey, deducir que se trata de una salamandra acuática (tritón) a partir de una pictura que ni es óptima ni fidedigna (la bestezuela parece un lagarto) sería caer en especulaciones. Para más detalles, vid. Antón (2021: 254, 256-258).

${ }^{40}$ Sobre los Emblemata (1596) de Lebey, Antón (2014, 2019 a/b y 2021). 
Ad S.al.am.undrim.

In milites.

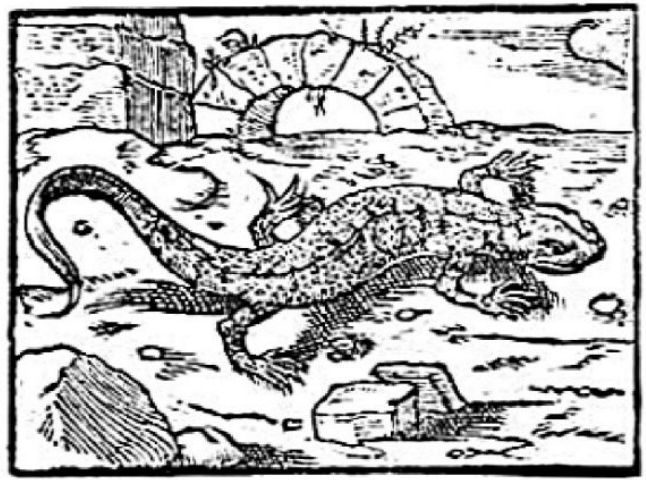

Imbrifer astumnus vitales addidit auras, Temperics fccit te Salamandra mori. Captat opes milestunc cum furialis Enio Enocat emeritos ad fer a bella duces: 2uid fipercu!f. iurentur foedera porca, Pauper in exigua deficit ille domo.

Figura 6: Coustau (1555: 95). URL: http://biblioteca.galiciana.gal/es. Dominio público.

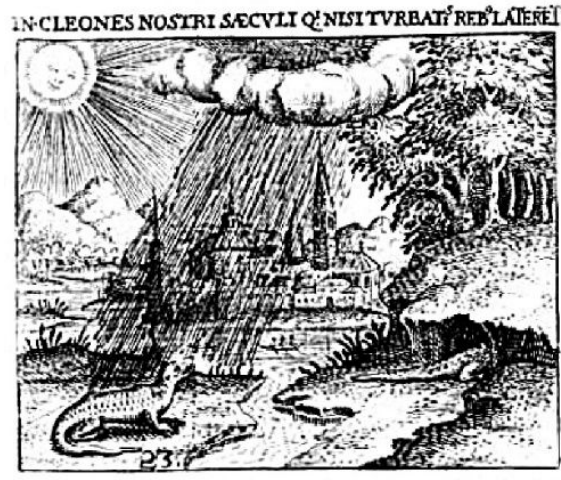

$V t$ quando calum nigrefctre copit ab Aufrib, Et ruir effu/a turbidus insber agur. Carpere iun demum vitales inripit autes, Temperie calipofl Salemardraperit. sic motu inser patria, bolliǵprecellas Quam noftris fervent omnia difidijs. Emergunt nuthiparsignotifsima vulgi, Solc jucrum patis qui redeunte latent.
Figura 7: Lebey (1596, emb. 23).

URL: https://archive.org. No copyright.

El título, de carácter descriptivo, expresa la res significata, que no se refleja en la pictura. Esta, en una narración visual simultánea, se divide en dos escenas: en la de la izquierda se ve una salamandra bajo la lluvia, y en la de la derecha, otra que se esconde en un tronco (el sol, que motiva la huida del caudado, está empero en la otra escena). La subscriptio, un epigrama de cuatro dísticos, explicita la semejanza entre el modus vivendi de la salamandra y los partidarios de cambios políticos (res novae): 
Vt quando coelum nigrescere coepit ab Austris ${ }^{41}$,

Et ruit effusa turbidus imber aequa.

Carpere tum demum vitales inripit [incipit $]$ auras $^{42}$,

Temperie coeli post Salamandra perit.

Sic motus inter patriae, bellique procellas

Quum nostris fervent omnia dissidijs.

Emergunt multi pars ignotissima vulgi,

Sole iterum pacis qui redeunte latent.

[ «Cuando el cielo comienza a oscurecerse con el soplo del Austro y una violenta tormenta se precipita en torrencial aguacero, entonces por fin la salamandra empieza a vivir, y después, cuando escampa, perece. De igual modo, en medio de los tumultos de la patria y las tormentas de la guerra, cuando todo bulle debido a nuestras discordias, salen muchos, la parte más ignota del vulgo, que, al volver el sol de la paz, se ocultan de nuevo»].

Si bien a Camerario no le pasaría desapercibida la ópoí $\omega \sigma \iota s$ erasmiana, las sospechosas concomitancias con el emblema de Lebey corroboran a este como su modelo directo iconográfico y literario: la res picta se asemeja mucho a la de Lebey, es análoga la res significans e incluso la res significata, pues los obscuri saepe homines \& quibus... ad victum suppeteret de Camerario evocan la pars ignotissima vulgi del epigrama (v. 7) de Lebey. Sin embargo, el emblematista alemán (o quizá su hijo Luis) silencia a su coetáneo francés, cuyos Emblemata, impresos en Fráncfort, circulaban exitosamente por Alemania y por el resto de Europa.

Retomemos la explanatio de Camerario. Esa inclinación a la guerra la amplifica con citas de Sinesio de Cirene y de Justino:

Non meminerunt illi, rem esse, ut Synesius dicit in Orat. de Regno, multo beatiorem pacem, quam bellum, quippe cum pacis causa bellici etiam apparatus fiant. Bellum igitur, ut de Hispania populis Iustinus [44, 2] inquit, quam otium malunt: Si extraneus deest, domi hostem quaerunt.

${ }^{41}$ El Austro (Auster) es el viento del sur que trae abundantes lluvias (Verg. Aen. 5, 696; georg. 1, 462; Tib. 1, 1, 47; Ov. met. 2, 21; etc.).

${ }^{42}$ Vitales auras, reminiscencia virgiliana (Aen. 1, 387). 
[«No recuerdan aquellos que, como dice Sinesio en el Discurso sobre el reino ${ }^{43}$, es una situación mucho más dichosa la paz que la guerra, pues incluso los preparativos bélicos se hacen por causa de la paz. Por consiguiente, como declara Justino $(44,2)$ de los pueblos de Hispania, prefieren la guerra a la paz: si les falta un extranjero, buscan el enemigo en la patria»].

Opina el autor que la crítica más importante de todas (Omnium autem graviss. ... exprobatio) es la que, en Homero, indirectamente hace Néstor tanto de Aquiles como de Agamenón (tam in Achillem, quam Agamemnonem): Sine cognatione, injustus, sine domo est ille / Qui bellum intestinum amat asperum [«Sin familia, sin respeto a la ley, sin hogar vive el que desea la cruel guerra intestina» ${ }^{44}$. Pero también -agrega- alaban la paz Aristófanes en Eirene [Pax 1096-1098 $]^{45}$, Aristóteles en la Política $[1,9,1253 \mathrm{a}]$ y Cicerón en la Filípica XIII [13, 1, 1]. Por último, sostiene que ayuda a comprender mejor este emblema el adagio (erasmiano) In seditione vel Androclides belli ducem agit [«En una sedición, incluso Andróclides dirige la guerra» $]^{46}$, que con otra variante lo citó ya nuestro autor a propósito de la anguila. Erasmo sostiene que este adagio se puede aplicar a los malos príncipes (ad malos principes), que ven mermado su poder cuando la situación pública está en calma (rebus pacatis minus valent in rep.), y por eso, a veces, provocan revueltas con sus artes tiránicas ( ob id aliquoties data opera rerum motus excitant arte tyrannica) a fin de saquear a su arbitrio más fácilmente al pueblo (quo commodius suo arbitratu populum compilent); o bien a algunos teólogos indignos de ese nombre (in theologos quosdam eo nomine indignos), que concitan disensiones y tumultos entre los cristianos (dissidium ac tumultus concitant in plebe Christiana), para alcanzar la celebridad

${ }^{43}$ Cf. Liber de regno bene administrando (1563: 17r): est quidem pax multo beatior, quam sit bellum, quippe cum ob pacem bellum suscipiatur.

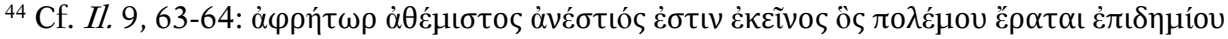

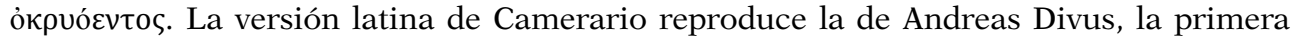
latina que se hizo de la Iliada y la Odisea, publicada en 1537 (utilizo la edición de Homero de, 1540: 90) y que, pese a su literalidad, fue durante siglos la principal traducción de Homero (Benedetto, 2005: 986 n. 80; 988-998; Fabbri, 1997; Petitmengin y Olsen, 1995).

${ }^{45}$ Sobre este célebre locus aristofánico, véase Antón (2019b: 267).

${ }^{46}$ Erasmo, adag. II.II.91 (Saladin, 2011: II, $136 \mathrm{n}^{\circ}$ 1191); en adag. II.1.12 (Saladin, 2011: II, $24 \mathrm{n}^{\circ}$ 1012) cita la variante In seditione etiam Androclides abjectissimus belli ducem agat [«En una sedición, incluso Andróclides, el más abyecto ciudadano, puede dirigir la guerra»]; véase Antón (2021: 263). 
aprovechando la ocasión (hac occasione celebres reddantur), y prefieren hacerse famosos a costa del mal común que vivir en el anonimato (maluntque publico omnium malo nobilitari quam inglorii viuere).

Ahora bien, la confesión luterana de Camerario ${ }^{47}$ lo lleva a escoger únicamente la segunda opción, que modifica para amoldarla al argumento del emblema: Quod Erasmus in rixosos Theologos, qui tantum $\dot{\varepsilon} \rho \iota \tau \tau$ ๙коіॅ suis scriptis clarescere, \& ex rebus ubique perturbatis ditescere cupiunt, rectissime accommodat [ "Erasmo lo emplea muy atinadamente contra los teólogos polemistas ${ }^{48}$, que tan solo desean alcanzar la gloria con sus escritos erísticos y enriquecerse con las revueltas que estallan por doquier»]. Para concluir, el emblematista pide al lector que añada a este el emb. 45 (Iunge cum hoc Emb. XLV) e insiste en la asociación entre ambos motivos.

\section{CONSIDERACIONES FINALES}

Los tres emblemas analizados son una representativa muestra del meditado catálogo natural que elaboró Camerario en sus Symbola et Emblemata. La elección del camello / dromedario (un cuadrúpedo), la anguila (un pez) y la salamandra / tritón (un anfibio) está motivada por la rara animalis proprietas, que hace de res significans y que figura en la res picta: el camello bebe agua revuelta, las anguilas se pescan revolviendo el agua, y la salamandra sale de su escondrijo solo con tiempo revuelto. Así pues, la palabra clave, presente en el título de los tres emblemas, es turbare ('revolver'), aplicada en sentido real al agua (Cent. II, 15; IV, 45) y a la climatología (Cent. IV, 70), y, en sentido metafórico, a los sediciosos y agitadores (res significata), elemento común que hace de estos emblemas una unidad.

Los tres emblemas encierran una críptica doctrina ética y política, e incluso religiosa (la fe luterana de Camerario aflora claramente en Cent.

${ }^{47} \mathrm{Su}$ padre, luterano también, tuvo una relación de amistad con Erasmo que luego se enfrió (Guenther, 2003: 247-248).

${ }^{48}$ Los filósofos de la escuela de Mégara dedicados a la dialéctica recibían el mote de

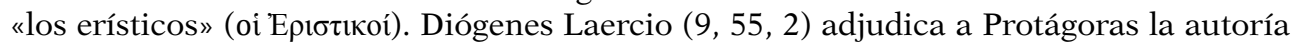

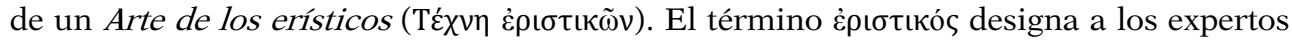
en el arte de disputar. 
IV, 45), que descifra en el comentario y avala con selectos excerpta y exempla greco-latinos, si bien sus directos inspiradores de la res picta, la res significans y la res significata fueron tres humanistas cultivadores del género emblemático: Giovio (Cent. II, 15), Alciato (Cent. IV, 45) y Lebey (Cent. IV, 70), siendo este último, coevo suyo, el único que Camerario (o su hijo Luis) opta por callar, como acostumbra hacer con otras fuentes.

Los tres animales, de especies dispares, representan per analogiam a los que sacan rédito de las rebeliones, ya sea promoviéndolas ellos mismos, significados por el camello y las anguilas, o mejor dicho, los anguillarum venatores (que enturbian el agua ad commoda sua), ya sea aprovechando los disturbios para enriquecerse y mejorar su estatus, designados estos últimos por la salamandra (que se deja ver solo con tiempo borrascoso). En suma, esta peculiar tríada zoológico-simbólica constituye un buen ejemplo de cómo Camerario identifica el magnum theatrum rerum naturalium con el magnum theatrum vitae humanae.

\section{BIBLIOGRAFÍA CITADA}

ADLER, A. (1935): Suidae Lexicon. Stuttgart: Teubner.

Alciato, A. (1546): Emblematum Libellus, nuper in lucem editus. Venetiis: apud Aldi filios.

ANTÓN, B. (2012): «Diarii omnes. La huella de Juan Luis Vives en los Symbola et Emblemata de Joaquín Camerario». Studia Philologica Valentina, 14, 157-170. ANTóN, B. (2014): «Los Emblemata (Frankfurt, 1596) de Dionysius Lebeus Batillius: Clasicismo, Neoestoicismo, Calvinismo». Janus. Estudios sobre el Siglo de Oro, 3, 115-176.

Antón, B. (2019a): «La (vera) Amicitia en los Emblemata (1596) de Denis Lebey de Batilly». En Alfaro, V. et al. (eds.): Studia Classica et Emblematica caro magistro Francisco J. Talauera Esteso dicata. Zaragoza: Libros Pórtico, 107157.

ANTÓN, B. (2019b): «La representación simbólica de la paz: la disputa por el patronazgo de Atenas en los Emblemata (Fráncfort, 1596; Heidelberg, 1600) de Denis Lebey Batilly». Euphrosyne, 47, 247-269.

ANTÓN, B. (2021): «La asociación simbólica entre la salamandra, Cleón y los pescadores de anguilas en los Emblemata (1596) de Denis Lebey». Veleia, 38, 251268. 
ANTÓN, B. y ESPINOSA, R. M. (2015): "Vulnere vulnera sano o el bálsamo de la mutua benevolencia». En López, S. y Maestre, J. M. (eds.): Studia Angelo Urbano dicata. Alcañiz-Madrid: Instituto de Estudios Humanísticos-FAEC, 1735.

ARBizzonI, G. (2007): "Imprese as Emblems. The European Reputation of an "Italian" Genre». En Mansueto, D. y Calogero, E. L. (eds.): The Italian Emblem: A Collection of Essays. Glasgow: University of Glasgow, 1-31.

AsHWORHT, W. Jr. (1990): «Natural History and the Emblematic World View». En Lindberg, D. C. y Wetsman, R. S. (eds.): Reappraisals of the Scientific Revolution. Cambridge-New York: CUP, 303-332.

ASHWORHT, W. Jr. (1996): «Emblematic Natural History of the Renaissance». En Jardine, N. et al. (eds.): Cultures of Natural History. Cambridge-New York: CUP, 17-37.

BEEKES, R. (2010): Etymological Dictionary of Greek. Leiden-Boston: Brill.

Belon, P. (1553): Petri Bellonii Cenomani De aquatilibus, libri duo, cum ziconibus [sic]. Parisiis: apud C. Stephanum.

Benedetto, G. (2005): «Le versioni latine dell’ Iliade». En Barbarisi, G. (ed.). Vincenzo Monti nella Cultura Italiana. Vol. I. Milano: Cisalpino, 961-1027.

BergK, Th. (1882): Poetae Lyrici Graeci. Vol. III. Lipsiae: in aedibus B. G. Teubneri.

BIEDERBICK, M. C. (2017): «Tradition and Empirical Observation-Nature in Giovio's and Symeoni's Dialogo dell'Imprese from 1574». En Enenkel y Smith (2017: 271-320).

BoISACQ, É. (1916): Dictionnaire étymologique de la langue grecque, étudiée dans ses rapports avec les autres langues indo-européennes. Heidelberg-Paris: Carl Winter-Klincksieck.

Bossuet, F. (1558): Francisci Boussueti [...] De natura aquatilium Carmen. Lugduni: apud Mathiam Bonhome.

CAMERARIO, J. (1590 [1593]): Symbolorum et Emblematum ex re herbaria desumtorum Centuria Vna collecta a Joachimo Camerario Medico Norimberg. [Colofón] Noribergae: Paulus Kaufmann.

CAMERARIO, J. (1595): Symbolorum et Emblematum ex quadrupedibus desumptorum Centuria Altera collecta a Joachimo Camerario Medi. Norimberg. [Colofón] Noribergae, Paulus Kaufmann.

CAMERARIO, J. (1596 [1597]): Symbolorum et Emblematum ex volatilibus et insectis desumtorum Centuria Tertia collecta a Joachimo Camerario Medi. Norimberg. [Colofón] Noribergae: Paulus Kaufmann. 
CAMERARIO, J. (1604 [1605]): Symbolorum et Emblematum ex aquatilibus et reptilibus desumptorum Centuria Quarta a Joachimo Camerario Medi. Nor. coepta: absoluta post eius obitum Ludouico Camerario I. Co . Ioch. Fil. [s. 1.]: [s. n.].

CAMERARIO, F. (1591): Operae horarum succisivarum, sive meditationes historicae. Althorphii: Typis Christophori Lochneri et Iohannis Hofmanni.

Camilli, S. (2013): «Orsini D’Aragona, Gentil Virginio». En Dizionario Biografico degli Italiani, vol. 79 (en línea: <http://www.treccani.it/enciclopedia/orsini-daragona-gentil-virginio_(Dizionario-Biografico)/>, consulta: 6 de noviembre de 2020).

CAPAccio, G. C. (1592): Delle imprese trattato [...] In tre Libri diviso. Napoli: ex officina Horatij Saluiani.

Chambry, E. (1927): Esope. Fables. Paris: Les Belles Lettres.

Chantraine, P. (1970): Dictionnaire étymologique de la langue grecque. Historire des mots, Vol. II: E-K. Paris: Klincksieck.

Coustau, P. (1555): Petri Costalii Pegma cum narrationibus philosophicis. Lugduni: apud Matthiam Bonhomme.

Duve, Th. (2003 [1889]): «Rittershausen, Konrad». En Neue Deutsche Biographie, 21, 670-671 (en línea: <https://www.deutsche-biographie.de/pnd1042886 39.html\#ndbcontent>, consulta: 6 de noviembre de 2020).

Eliano, C. (1565): Aeliani De historia animalium libri XVII, quos ex integro ac veteri exemplari Graeco, Petrus Gillius vertit. Lugduni: apud Guliel. Rouillium.

ENENKEL, K. A. E. (2018): «Early Modern Zoology as a Mirror of Princes: Joachim Camerarius' Quadrupedes (1595)». En The Invention of the Emblem Book and the Transmission of Knowledge, ca. 1510-1610. Leiden: Brill, 313-364 (= Enenkel y Smith, 2017, 91-148).

ENENKel, K. A. E. y SMith, P. J. (eds.) (2017): Emblems and the Natural World. Leiden: Brill.

FABBRI, R. (1997): «Sulle traduzioni latine umanistiche da Omero». En Pittaluga, S. y Montanari, F. (ed.): Posthomerica. Genova: Università di Genova, 99-124. Flonta, T. (2012): A Dictionary of English and Romance Languages Equivalent Proverbs. Tasmania: DeProverbio.com.

GARCÍA ARRANZ, J. J. (1990): «La salamandra: distintas interpretaciones gráficas de un mito literario tradicional». Norba: Revista de Arte, 10, 53-68.

GAZA, Th. (1524): Aristotelis De historia animalium libri IX. [...] Theodoro Gaza interprete. Parisiis: Ex officina Simonis Colinaei. 
GeSNer, C. (1551): Conradi Gesneri medici Tigurini Historiae Animalium Liber I. de Quadrupedibus uiuiparis. Tiguri: apud Christophum Froschouerum.

GESNER, C. (1554): Historiae animalium Liber II, De quadrupedibus oviparis. Tiguri: apud Christophum Froschouerum.

Gesner, C. (1558): Conradi Gesneri medici Tigurini Historiae animalium liber IIII, qui est de piscium et aquatilium animantium natura. Tiguri: apud Christophum Froschouerum.

GESNER, C. (1560): Icones animalium quadrupedum viviparorum et oviparorum, quae in historiae animalium Conradi Gesneri libro I et II describuntur [...]. Editio Secunda, nouis eiconibus non paucis [...]. Tiguri: Excudebat C. Froschouerus.

Giovio, P. (1555): Dialogo dell'imprese militari e amorose. Roma: Antonio Barre.

Giovio, P. (1559): Dialogo dell'imprese militari e amorose. Lione: Guglielmo Roviglio.

Guenther, I. (2003): «Joachim Camerarius». En Bietenholz, P. G. y Deutscher, Th. B. (eds.): Contemporaries of Erasmus: A Biographical Register of the Renaissance and Reformation. Vol. I: $A-E$. Toronto: University of Toronto Press, 247-248.

Harms, W. y Kuechen, U. B. (1986-1988) (eds.): Joachim Camerarius, Symbola et emblemata. 1: Centuria I-III; 2: Centuria IV (Nürnberg 1590 bis 1604]. Graz: Akademische Druck- u. Verlagsanstalt.

Harms, E. W. y Hess, G. (2009) (eds.): Joachim Camerarius d. J., Symbola et Emblemata tam moralia quam sacra. Die hand-schriflichen Embleme von 1587. Tübingen: W. de Gruyter.

HenKel, A. y SchÖNE, A. (2013): Emblemata: Handbuch zur Sinnbildkunst des $X V I$. und XVII. Jahrhunderts. Stuttgart: Metzler.

HENDRIKX, S. (2017): «Ichthyology and Emblematics in Conrad Gesner's Historia piscium and Joachim Camerarius the Younger's Symbola et emblemata». En Enenkel y Smith (2017: 184-226).

Homero (1540): Homeri Ilias, Andrea Divo Iustinopolitano interprete, ad verbum translata. [...]. Odyssea, Andrea Divo Iustinopolitano interprete, ad verbum translata. [...]. Venetiis: apud D. Iacob a Burgofrancho Papiensem.

Horozco y Covarrubias, J. de (1589): Emblemas morales. Segovia: Juan de la Cuesta.

Höschel, D. (1595), Hieroglyphica Horapollinis a Davide Hoeschelio, Fide Codicis Augustani Ms correcta, suppleta, illustrata. Augustae Vindelicorum: [s. n.]. 
KOHLNDORFER-FrIES, R. (2009): Diplomatie und Gelehrtenrepublik: Die Kontakte des französischen Gesandten Jaques Bongars (1554-1612). Berlin: W. de Gruyter.

Kusukawa, S. (2010): «The Sources of Gessner's Pictures for the Historia Animalium». Annals of Science, 67.3, 303-328.

LA PERRIÈRE, G. de (1544): Le Theatre des Bons engins. Paris: Denis Janod.

LEBEY, D. (1596): Dionysii Lebei Batillii [...] Emblemata. Emblemata a Jano Jac. Boissardo Vesuntino delineata sunt, et a Theodoro de Bry sculpta, et nunc recens in lucem edita. Francofurti ad Moneum: De Bry.

LENK, L. (1972): «Höschel, David». En Neue Deutsche Biographie, 9, 368-369 (en línea: <https://www.deutsche-biographie.de/pnd118705695.html\#ndbcontent $>$, consulta: 6 de noviembre de 2020).

Lutero, M. (1525): De traditionibus humanis vitandis: Item de iniquo Mammōne, Lucae XVI, contiones. Martino Luthero Authore. Basileae: Excudebat Thomas Volffius.

Margolin, J. C. (ed.) (1975): Parabolae sive similia. En Opera Omnia Desiderii Erasmi Roterodami Recognita et Adnotatione Critica Instructa Notisque Illustrata, Ordinis Primi Tomus Quintus. Amsterdam-Oxford: North-Holland Publishing Company.

Mattioli, P. A. (1554): Petri Andreae Matthioli [...] Commentarii, in libros sex Pedacii Dioscoridis Anazarbei, De medica materia. Venetiis: in officina Erasmiana, apud Vincentium Valgrisium.

PAPY, J. (2003): «Joachim Camerarius's Symbolorum et Emblematum Centuriae Quatuor. From Natural Sciences to Moral». En Enenkel, K. A. E. y Visser, A. S. Q. (eds.): Mundus Emblematicus. Turnhout: Brepols, 201-234.

Petitmengin, P. y Olsen, B. M. (1995): «Bibliographie de la réception de la littérature classique du IXe au XVe siècle». En Leonardi, C. y Olsen, B. M. (eds.): The Classical Tradition in the Middle Ages and the Renaissance. Spoleto: Centro italiano di Studi sull'Alto Medioevo, 199-274.

PitToni, B. (1562): Imprese di diversi Prencipi, Duchi, signori e d'altri [...] stanze del Dolce che dichiarano i motti di esse imprese. Venetia: [s. n.].

SALAdIN, J. C. (2011): Les Adages d'Érasme. Paris: Les Belles Lettres (5 vols.).

SCHUBERT, F. H. (1955): Ludwig Camerarius, 1573-1651. Eine Biographie. München: Kallmünz.

SINESIO DE CIRENE (1563): Synesii Episcopi Cyrenes Liber de regno bene administrando liber [...] Stanislae Ilouio Polono interprete. Venetiis: apud Io. Baptistam Somascum. 
SMITH, P. J. (2017): «Joachim Camerarius's Emblem Book on Birds (1596), with an Excursus on America's Great Seal». En Enenkel y Smith (2017: 149-183).

SPARREBOom, M. (2014): Salamanders of the Old World. The Salamander of Europe, Asia and Northern Africa. Zeist: The Netherlands, KNNV Publishing.

SPRINGER, C. P. E. (2011): Luther's Aesop. Kirksville (Missouri): Truman State U. P.

Tomasi, L. T. y WiLLIS, T. (2009): An Oak Spring Herbaria: Herbs and Herbals from the Fourteenth to the Nineteenth Centuries: A Selection of the Rare Books, Manuscripts and Works of Art in the Collection of Rachel Lambert Mellon. New York: Yale U. P.

VELO-ANTÓN, G. y BuCKLEY, D. (2015): «Salamandra común - Salamandra salamandra». En Salvador, A. y Martínez, I. (eds.): Enciclopedia Virtual de los Vertebrados Españoles. Madrid (en línea: <http://digital.csic.es/bitstream/10261/ 126 388/6/salsal_v1.pdf>, consulta: 6 de noviembre de 2020).

Beatriz ANTÓN

Universidad de Valladolid beatriz@fyl.uva.es https://orcid.org/0000-0003-3050-2733 
